\title{
Rifampin-Resistant Cutibacterium (formerly Propionibacterium) namnetense Superinfection after Staphylococcus aureus Bone Infection Treatment
}

\author{
Stéphane Corvec ${ }^{1,2,3}$, Aurélie Guillouzouic ${ }^{1}$, Guillaume Ghislain Aubin¹, Sophie Touchais,3,4, Olivier \\ Grossi ${ }^{3,5}$, François Gouin ${ }^{3,4}$, Pascale Bémer ${ }^{1,3}$ \\ 1. Service de Bactériologie-Hygiène hospitalière, $\mathrm{CHU}$ de Nantes, Nantes, France \\ 2. CRCINA, INSERM, Université d'Angers, Université de Nantes, Nantes, France \\ 3. Nantes study group member of CRIOGO (Centre de Référence des Infections Ostéo-articulaires du Grand Ouest), Nantes, France \\ 4. Clinique chirurgicale orthopédique et traumatique, $\mathrm{CHU}$ de Nantes, Nantes, France. \\ 5. Service de Maladies infectieuses, CHU de Nantes, Nantes, France - Département de Médecine Interne -Infectiologie, Nouvelles Cliniques Nantaises, \\ Nantes, France \\ $\square$ Corresponding author: Stéphane Corvec, CHU de Nantes, Institut de Biologie, Service de Bactériologie-Hygiène hospitalière, 9, quai Moncousu 44093 Nantes \\ Cedex 1. Email : stephane.corvec@chu-nantes.fr; Phone: +33 24008 39 55; Fax: +33 240083928 \\ (c) Ivyspring International Publisher. This is an open access article distributed under the terms of the Creative Commons Attribution (CC BY-NC) license \\ (https:// creativecommons.org/licenses/by-nc/4.0/). See http://ivyspring.com/terms for full terms and conditions.
}

Received: 2018.09.17; Accepted: 2018.10.25; Published: 2018.11.24

\begin{abstract}
After rifampin and levofloxacin treatment for a Staphylococcus aureus bone infection, a pyogenic granuloma due to a newly described Cutibacterium species, $C$. namnetense developed on the tibia former external fixator. This rifampin resistant bacterium, selected during treatment, harbored a mutation in the $r p o B$ gene. This case illustrates the possible in vivo selection of resistant mutant most likely due to the bacterial burden and therefore the importance of adequate bone infection treatment.
\end{abstract}

Key words: bone infection, rifampin, Cutibacterium namnetense, Staphylococcus aureus, resistance

\section{Introduction}

Staphylococcus aureus persists as a leading cause of bone or implant-associated infections [1]. After an initial intravenous therapy, a prolonged treatment course is required and if possible, a switch to an oral combination treatment is recommended [2]. In parallel, the pathogenicity of Cutibacterium species has long been restricted to skin conditions [3] whereas Cutibacterium acnes is increasingly recognized as a pathogen mainly involved in foreign-body infections [4]. The aim of this study was to report the first Cutibacterium namnetense infection and how this new pathogenic Cutibacterium species from the skin microbiota emerged after a $S$. aureus infection treatment. In this issue, rifampin, a bactericidal antibiotic that diffuses well in bone tissue and bacterial biofilm, plays a key role in bone and joint infections. Indeed, it remains the cornerstone of the
Gram-positive bacteria osteoarticular infections treatment, especially those including device-related infections.

A 21 years-old man was admitted for an open fracture of tibia and fibula (Cauchoix classification 2) after a traffic accident. Initial surgical treatment consisted of an external fixator to the tibia and intra-medullary wires in fibula. Two months after initial surgery, the patient presented skin necrosis and pseudarthrosis as judged from the computed tomography scan. Blood leukocyte count and C-reactive protein level were normal. A two-stage surgery was decided to treat the pseudarthrosis. The second stage of surgery relied on consolidation of the tibia using an intramedullary rod during which five tissue samples were collected and antibiotic therapy was started using vancomycin (2g/day) and 
gentamicin (200 mg/day). In culture, after one day of incubation at $37^{\circ} \mathrm{C}$, all samples were positive for $S$. aureus. The isolate was fully susceptible except for erythromycin. Antibiotic therapy was switched to oral combination including levofloxacin (500 $\mathrm{mg}$ / day) and rifampin (1200 mg/day) for twelve weeks. One year later, a pyogenic granuloma developed on the screw of the former external fixator, suggesting an underlying infection. Treatment consisted of material removal associated with cloxacillin (4g/day) and gentamicin ( $200 \mathrm{mg} /$ day) treatment. After 4 days of incubation, cultures of four out of five samples (subcutaneous, biopsy and bone samples) were positive for an anaerobic Gram-positive rod identified as Cutibacterium sp. After complementary identification investigations using phenotypic, genetic, chemotaxonomic and phylogenetic methods, the microorganism was finally identified as the newly described species, Cutibacterium namnetense [5]. Importantly, this species can be misidentified but genome sequencing confirmed that this microorganism represents a distinct, albeit close relative to $C$. acnes [6]. In vitro antimicrobial susceptibility tests using Etest method revealed a susceptibility to amoxicillin and levofloxacin (Minimal Inhibitory Concentration $=0.25 \mathrm{mg} / \mathrm{L}$ ), and a rifampinresistance (MIC > $32 \mathrm{mg} / \mathrm{L}$ ). The treatment was changed to amoxicillin ( $6 \mathrm{~g}$ per day) for two months. Clinical outcome was favorable after a four years follow-up.

To characterize the rifampin resistance, DNA from this clinical resistant isolate was extracted using the InstaGene Matrix method (Bio-Rad Laboratories, Hercules, CA, USA). Six overlapping regions of the $r p o B$ gene were amplified by PCR and sequenced as previously described [7]. The obtained rpoB gene sequence was compared to the $r p o B$ gene sequence of a C. acnes reference strain KPA171202. Due to their genomic and phylogenetic similarities and the average nucleotide identity value being $88.5 \%$ [6] (Genbank accession number NC006085), comparisons revealed a single mutation at position 440 leading to a substitution from His to Arg and conferring high-level rifampin resistance. This mutation has been previously reported in C. acnes clinical isolates [7]. Here, the treatment of the first $S$. aureus infection consisted in rifampin combined with levofloxacin during twelve weeks, following IDSA guidelines [8]. Interestingly, a superinfection at the same site with another bacterial species (C. namnetense) occurred. This bacterial species, originating most probably from the skin microbiota, was selected by the first treatment, aiming at treating the S. aureus infection. In the present study, three arguments could explain the resistance development in $C$. namnetense: (i) the $C$. namnetense high inoculum during this infection (four out of five samples were positive in culture in four days with numerous colonies, leading to a tibia pandiaphysitis linked to the former external fixator (portal of entry), (ii) the levofloxacin MIC $(0.25 \mathrm{mg} / \mathrm{L})$ that might be less protective than moxifloxacin $(\mathrm{MIC}=$ $0.06 \mathrm{mg} / \mathrm{L}$ ) for rifampin mutant selection, (iii) the high-mutation frequency induced by rifampin [9], highlighting the reason why rifampin should not be prescribed alone [2]. Therefore, rifampin might have selected resistant bacteria within an important inoculum including opportunistic ones. Indeed, Cutibacterium species are commensal bacteria belonging to skin flora and mostly involved in implantassociated infections [3]. Cutibacterium namnetense is an opportunistic pathogen, selected mainly by rifampin treatment. The mutation that confers rifampin resistance found in $r p o B$ gene (cluster I) was already described in C. acnes, in vitro [10]. The position 440 represents a hot spot in $r p o B$ gene. In this case, we hypothesize that because of potential diffusion discrepancies at the beginning, one of the antibiotics was alone at the site of infection, allowing a possible selection of resistant mutants due to high bacterial burden [11]. This way, we emphasize the importance of combining agents, particularly because rifampin and levofloxacin as monotherapy may promote the selection of resistant mutants, as recently reported [2].

A similar rifampin-susceptible $C$. namnetense SK182B-JCVI was identified on the skin during the Human Microbiome Project (NZ_AFUN00000000.1). Both strains share $99.52 \%$ of similarity at the genomic level according to the ANI value [5].

The acquisition of high-level resistance to rifampin remains rare. Indeed, other isolates recovered from femur and scalp osteitis in our routine laboratory demonstrated rifampin susceptibility (data not shown). Nevertheless, microbiologists and physicians should be aware of the potential risk of resistant mutant selection with the emergence of such strains after long-term treatment, especially in poorly vascularized infection sites. This relevant case constitutes the first description of Cutibacterium namnetense infection, a new species from skin microbiota with an acquired rifampin resistance most likely due to a high bacterial burden.

\section{Acknowledgment}

We would like to thank all the members of the Nantes CRIOGO network.

\section{Author contributions}

ST, FG and OG are the attending physicians for the patient and collected medical data of the patient. SC, GGA, AG and PB performed microbiological 
analysis of the clinical samples and discussed the case with surgeons and infectious medical doctors. AG and GGA performed the susceptibility testing and molecular identification of the strain. SC and AG wrote the manuscript. PB, ST and GGA made a critical revision of the manuscript. All authors read and approved the final manuscript.

\section{Competing Interests}

The authors have declared that no competing interest exists.

\section{References}

[1] Aubin GG, Lavigne JP, Guyomarch B, et al. Staphylokinase and ABO group phenotype:new players in Staphylococcus aureus implant-associated infection development. Future Microbiol. 2015;10:1929-1938.

[2] Aubin GG, Bémer P, Guillouzouic A, et al. Failure of combination therapy for Staphylococcus aureus bone infection: a case of in vivo selection with resistance to rifampicin and fusidic acid. Infect Dis Lond Engl. 2016;48:699-702.

[3] Aubin GG, Portillo ME, Trampuz A, et al. Propionibacterium acnes, an emerging pathogen: From acne to implant-infections, from phylotype to resistance. Med Mal Infect. 2014;44:241-250.

[4] Portillo ME, Corvec S, Borens $\mathrm{O}$, et al. Propionibacterium acnes: an underestimated pathogen in implant-associated infections. BioMed Res Int. 2013:804391.

[5] Aubin GG, Bémer P, Kambarev S, et al. Propionibacterium namnetense sp. nov., isolated from a human bone infection. Int J Syst Evol Microbiol. 2016;66:3393-3399.

[6] Aubin GG, Kambarev S, Bémer P, et al. Draft Genome Sequence of Highly Rifampin-Resistant Propionibacterium namnetense NTS 31307302T Isolated from a Patient with a Bone Infection. Genome Announc. 2016:11;4.

[7] Furustrand Tafin U, Aubin GG, Eich G, et al. Occurrence and new mutations involved in rifampicin-resistant Propionibacterium acnes strains isolated from biofilm or device-related infections. Anaerobe. 2015:34;116-119.

[8] Osmon DR, Berbari EF, Berendt AR, et al. Diagnosis and management of prosthetic joint infection: clinical practice guidelines by the Infectious Diseases Society of America. Clin Infect Dis. 2013;56:e1-e25.

[9] Aubry-Damon H, Soussy CJ, Courvalin P. Characterization of mutations in the $r p o B$ gene that confer rifampin resistance in Staphylococcus aureus. Antimicrob Agents Chemother. 1998;42:2590-2594.

[10] Furustrand Tafin U, Trampuz A, Corvec S. In vitro emergence of rifampicin resistance in Propionibacterium acnes and molecular characterization of mutations in the rpoB gene. J Antimicrob Chemother. 2013;68:523-528.

[11] Drancourt M, Stein A, Argenson JN, et al. Oral treatment of Staphylococcus spp. infected orthopaedic implants with fusidic acid or ofloxacin in combination with rifampicin. J Antimicrob Chemother. 1997;39:235-240. 